\title{
Impact of a high loading dose of amikacin in patients with severe sepsis or septic shock
}

\author{
Nicolas Allou ${ }^{1 *}$, Astrid Bouteau², Jérôme Allyn ${ }^{1}$, Aurélie Snauwaert ${ }^{2}$, Dorothée Valance ${ }^{1}$, Julien Jabot ${ }^{1}$, \\ Bruno Bouchet ${ }^{1}$, Richard Galliot ${ }^{1}$, Laure Corradi ${ }^{1}$, Philippe Montravers ${ }^{2}$ and Pascal Augustin ${ }^{2}$
}

\begin{abstract}
Background: The therapeutic effect of aminoglycosides is highest and optimal when the peak plasma concentration $\left(C_{\max }\right) /$ minimal inhibitory concentration $(\mathrm{MIC})$ ratio is between 8 and 10 . The French guidelines recommend to use high doses of aminoglycosides for empiric antibiotic therapy in patients suffering from severe sepsis or septic shock. In clinical practice, the recommended target is an amikacin $C_{\max }$ between 60 and $80 \mathrm{mg} / \mathrm{L}$, which corresponds to approximately 8 times the MIC breakpoint, as defined by the European Committee on Antimicrobial Susceptibility Testing. The aim of this study was to assess the incidence and impact on mortality of an amikacin concentration between 60 and $80 \mathrm{mg} / \mathrm{L}$ in patients suffering from severe sepsis or septic shock.
\end{abstract}

Methods: This was a prospective observational cohort study conducted in two intensive care units (ICU). Patients receiving amikacin at a loading dose of $30 \mathrm{mg} / \mathrm{kg}$ for severe sepsis or septic shock were enrolled in the cohort. The target $C_{\max }$ for amikacin was between 60 and $80 \mathrm{mg} / \mathrm{L}$, as recommended by French guidelines (i.e. $C_{\max } / \mathrm{MIC}$ breakpoint $=8-10$ ).

Results: Over the study period, the amikacin $C_{\max }$ was $<60 \mathrm{mg} / \mathrm{L}$, between 60 and $80 \mathrm{mg} / \mathrm{L}$, and $>80 \mathrm{mg} / \mathrm{L}$ in 20 (18.2\%), $46(41.8 \%)$ and $44(40 \%)$ of the 110 selected patients, respectively. Mortality rate was $40,28.3$ and $56.8 \%$ in the groups of patients with $C_{\max }<60 \mathrm{mg} / \mathrm{L}, 60 \mathrm{mg} / \mathrm{L}<C_{\max }<80 \mathrm{mg} / \mathrm{L}$ and $C_{\max }>80 \mathrm{mg} / \mathrm{L}$, respectively. Following multivariate analysis, mortality rate was significantly lower in the group of patients with amikacin $C_{\max }$ between 60 and $80 \mathrm{mg} / \mathrm{L}$ than in the group of patients with amikacin $C_{\max }>80 \mathrm{mg} / \mathrm{L}(P=0.004)$. The multivariate analysis also revealed that the factors independently associated with a higher in-ICU mortality rate were age $(P=0.02)$ and norepinephrine dose $(P=0.0001)$.

Conclusions: With a loading dose of $30 \mathrm{mg} / \mathrm{kg}$ of amikacin, concentration was potentially suboptimal $\left(C_{\max }<60 \mathrm{mg} / \mathrm{L}\right.$ ) in only $18.2 \%$ of patients. The pharmacodynamic target $\left(60 \mathrm{mg} / \mathrm{L}<C_{\max }<80 \mathrm{mg} / \mathrm{L}\right.$ ) recommended by French guidelines was reached in $41.8 \%$ of patients and was associated with reduced in-ICU mortality. But amikacin overexposure (i.e. $C_{\max }>80 \mathrm{mg} / \mathrm{L}$ ) was frequent and potentially associated with increased mortality.

Keywords: Amikacin, Pharmacokinetics/pharmacodynamics, Severe sepsis/septic shock

\section{Background}

The usefulness of antimicrobial combination therapy, such as the use of aminoglycosides in patients with severe

\footnotetext{
*Correspondence: nicolas.allou@hotmail.fr

${ }^{1}$ Réanimation polyvalente, Hôpital Felix Guyon, Centre Hospitalier Universitaire Felix Guyon, Allée des Topazes, Bellepierre, 97405 Saint Denis, France

Full list of author information is available at the end of the article
}

sepsis or septic shock, remains controversial [1, 2]. Nevertheless, early and appropriate antimicrobial therapy in septic shock patients has been reported to reduce inhospital mortality [2]. In view of this, aminoglycosides are often combined with another antibiotic in patients with severe sepsis or septic shock in order to broaden the treatment's spectrum of activity and obtain bactericidal synergy. The therapeutic effect of aminoglycosides 
is highest and optimal when the peak plasma concentration $\left(C_{\max }\right) /$ minimal inhibitory concentration (MIC) ratio is between 8 and 10 [3]. However, in patients with severe sepsis or septic shock, aminoglycosides are frequently used in empiric antimicrobial treatment without the causal micro-organisms and their MICs being identified. The French guidelines recommend to use high doses of aminoglycosides for empiric antibiotic therapy in patients suffering from severe sepsis or septic shock, and, specifically, doses of $25-30 \mathrm{mg} / \mathrm{kg}$ in the case of amikacin $[4,5]$. In clinical practice, the recommended target is an amikacin $C_{\max }$ between 60 and $80 \mathrm{mg} / \mathrm{L}$ [4], which corresponds to approximately 8-10 times the MIC breakpoint, as defined by the European Committee on Antimicrobial Susceptibility Testing (EUCAST) of Pseudomonas aeruginosa and Enterobacteriaceae [5]. Previous studies have shown that a loading dose of $25 \mathrm{mg} / \mathrm{kg}$ frequently leads to a suboptimal amikacin $C_{\max }(>30 \%$ of patients with $C_{\max }<60 \mathrm{mg} / \mathrm{L}$ ) [6, 7], prompting an increase in the loading dose to $30 \mathrm{mg} / \mathrm{kg}$ without improving outcomes $[8,9]$. Yet the dose of $30 \mathrm{mg} / \mathrm{kg}$ has been evaluated in a limited number of patients $(n<50)[8,9]$. The aim of this study was to assess the incidence and impact on mortality of an amikacin concentration between 60 and $80 \mathrm{mg} / \mathrm{L}$ in patients suffering from severe sepsis or septic shock.

\section{Methods}

The present observational study was approved by the Ethics Committee of Félix Guyon University Hospital (R15003). The requirement to obtain written informed consent from patients was waived, as the study was noninterventional and followed our usual protocol. However, all patients or their legally authorised representative was verbally informed about the process of data collection and could refuse to participate.

The reporting of this study complies with the Strengthening the Reporting of Observational studies in Epidemiology recommendations statement [10].

\section{Selection of the study sample}

This prospective observational cohort study was conducted from April 2015 to December 2015 in one mixed medical/surgical ICU and in one surgical ICU at two French university hospitals.

All patients were over 18 years old and treated for severe sepsis or septic shock with a combination therapy of amikacin at a loading dose of $30 \mathrm{mg} / \mathrm{kg}( \pm 2.5 \mathrm{mg} / \mathrm{kg})$ on the day of enrolment.

The first dose of amikacin was calculated using the total body weight of the day for patients with a body mass index $<30 \mathrm{~kg} / \mathrm{m}^{2}$. For patients with a body mass index $\geq 30 \mathrm{~kg} / \mathrm{m}^{2}$, the dose was calculated using the adjusted body weight, which was calculated as follows: ideal body weight (height $(\mathrm{cm})-100-[$ height $(\mathrm{cm})-150] / 4$ for male gender and height $(\mathrm{cm})-100-$ [height $(\mathrm{cm})-150] / 2$ for female gender) +0.4 [total body weight at admission-ideal body weight].

Severe sepsis and septic shock were defined following the Surviving Sepsis Campaign guidelines [11].

Only the first day of amikacin administration was studied.

The prescribed duration of the continuous infusion was 30 min. Measurements of $C_{\max }$ and trough concentration were taken $30 \mathrm{~min}$ and $24 \mathrm{~h}$ after the end of infusion. All samples were analysed immediately. Amikacin dosages were measured using a fluorescence polarisation immunoassay [12].

Trough concentration was considered elevated if $>2.5 \mathrm{mg} / \mathrm{L}$ and was assessed only if treatment length was $>5$ days or in cases of renal insufficiency, as recommended by French guidelines [4, 6].

The exclusion criteria were: treatment with amikacin within 7 days prior to inclusion; inappropriate dose of amikacin $(<27.5$ or $>32.5 \mathrm{mg} / \mathrm{kg})$; inappropriate duration of amikacin infusion ( $<25$ or $>35 \mathrm{~min}$ ); and inappropriate delays in measuring the amikacin $C_{\max }(<20$ or $>40 \mathrm{~min}$ after the end of infusion).

\section{Data collected and study endpoint}

Patient comorbidities at ICU admission were recorded on inclusion.

After administering the loading dose of $30 \mathrm{mg} / \mathrm{kg}$ of amikacin, the main endpoint was to evaluate the impact of the amikacin $C_{\max }$ on the in-ICU mortality of patients with severe sepsis or septic shock.

\section{Statistical analysis}

Results were expressed as total number (percentage) for categorical variables and as median [25th-75th percentiles] for continuous variables. Continuous variables were compared using the Mann-Whitney test or the KruskalWallis test, as appropriate. Categorical variables were compared using the Chi-square test or the Fisher's exact test, as appropriate. Risk factors for in-ICU mortality in bivariate analysis with $P<0.1$ were entered into a multivariate logistic regression analysis using backward selection with $P<0.05$.

We considered that 50 patients were needed in the non-survivors group to perform a multivariate analysis with ten variables [13]. Based on an in-ICU mortality rate of $50 \%$ in patients with severe sepsis or septic shock [6], we calculated that 100 patients had to be included in the study cohort for there to be a minimum of 50 patients in the non-survivors group. Collinearity between independent factors was investigated. When identified, the most clinically relevant factor was chosen for use in the 
multivariate model. A $P$ value $<0.05$ was considered significant. Analyses were performed using SAS statistical software (8.2, Cary, NC, USA).

\section{Results}

\section{Study population}

Over the study period, 921 patients were hospitalised, of which $150(16.3 \%)$ received amikacin for severe sepsis or septic shock. Among the latter, 40 were excluded: 15 had received aminoglycosides in the previous seven days; 15 had received an inappropriate dose of amikacin; and 10 had an incorrect $C_{\max }$ measurement taken. The remaining 110 patients formed the cohort.

Patient characteristics on ICU admission and study inclusion are shown in Tables 1, 2 and 3.

The median age was 61 [51-70], the median Simplified Acute Physiology Score 2 at admission was 54 [4168], and the median SOFA score on the day of amikacin administration was 10 [8-11]. The sources of infection were respiratory in 57 cases (51.8\%), intra-abdominal in 16 cases $(14.5 \%)$ and catheter related in 9 cases $(8.2 \%)$. Bacteraemia was present in 32 cases (29.1\%) (Table 3).

The most frequently isolated bacteria were $P$. aeruginosa (19.1\%), Enterobacter spp. (16.7\%) and Escherichia coli (13.9\%) (Table 3).

\section{Amikacin dosages}

The median dose of amikacin was 30 [29.2-30.6] mg/kg. Pharmacodynamic amikacin targets $\left(60 \mathrm{mg} / \mathrm{L}<C_{\max }<\right.$ $80 \mathrm{mg} / \mathrm{L}$ ) were achieved in 46 of the 110 patients (41.8\%). Forty-four of the 110 patients $(40 \%)$ had a $C_{\max }>80 \mathrm{mg} / \mathrm{L}$, and 20 of the 110 patients $(18.2 \%)$ had a $C_{\max }<60 \mathrm{mg} / \mathrm{L}$. No patient had a $C_{\max }<30 \mathrm{mg} / \mathrm{L}$ (Table 4).

Trough concentration was measured for 65 patients (68.2\%). Among these, 51 (78.5\%) had a trough concentration $>2.5 \mathrm{mg} / \mathrm{L}$.

\section{Prognosis}

The in-ICU mortality rate was $41.8 \%$. A univariate analysis revealed that the amikacin $C_{\max }$ was not associated with a reduction in the in-ICU mortality rate $\left(C_{\max }\right.$ was 73.6 [65.9-83.6] $\mathrm{mg} / \mathrm{L}$ in survivors and 81.9 [66.5-89.7] $\mathrm{mg} / \mathrm{L}$ in non-survivors, $P=0.12$ ).

The univariate analysis also showed that the in-ICU mortality rate was lower in the group of patients with a $C_{\max }$ between 60 and $80 \mathrm{mg} / \mathrm{L}(28.3 \%)$ than in patients with a $C_{\max }>80 \mathrm{mg} / \mathrm{L}(56.8 \%, P=0.006)$.

Moreover, there was no statistically significant difference of mortality between the group of patients with a $C_{\max }$ between 60 and $80 \mathrm{mg} / \mathrm{L}$ and the group of patients with a $C_{\max }<60 \mathrm{mg} / \mathrm{L}(40 \%, P=0.18)$.
The univariate analysis of trough concentration measurements in 75 of the 110 patients (68.2\%) revealed that a higher amikacin trough concentration was not associated with a higher in-ICU mortality rate (5.2 [2.3-10.4] $\mathrm{mg} / \mathrm{L}$ in survivors versus 8.6 [4.2-14.3] $\mathrm{mg} / \mathrm{L}$ in non-survivors, $P=0.058$ ).

The proportion of micro-organisms with a greater than usual amikacin MIC (i.e. non-fermenting Gram-negative bacilli) in non-survivors was similar to that in survivors (16 of 64 in survivors group versus 6 out of 46 in nonsurvivors group, $P=0.12$ ).

The other risk factors found to be predictive of in-ICU mortality (based on a bivariate analysis with $P<0.1$ ) are exposed in Table 2.

Following multivariate analysis, compared to a $C_{\max }$ between 60 and $80 \mathrm{mg} / \mathrm{L}, C_{\max }>80 \mathrm{mg} / \mathrm{L}$ was associated with a higher probability of mortality (OR 95\% CI 3.96 [1.54-10.2], $P=0.004)$, and $C_{\max }<60 \mathrm{mg} / \mathrm{L}$ was not associated with a higher probability of mortality (OR $95 \%$ CI 1.92 [0.46-8.24], $P=0.4)$. The multivariate analysis also revealed that the factors independently associated with a higher mortality rate were a higher age $(P=0.02)$ and a higher norepinephrine dose $(P=0.0001)$ (Table 5).

In survivors, acute kidney injury was not associated with a $C_{\max }>80 \mathrm{mg} / \mathrm{L}$ ( $15.8 \%$ of patients who developed acute kidney injury had a $C_{\max }>80 \mathrm{mg} / \mathrm{L}$, while $14.2 \%$ who did not had a $C_{\max }>80 \mathrm{mg} / \mathrm{L}, P=0.88$ ).

An amikacin trough concentration $>2.5 \mathrm{mg} / \mathrm{L}$ was not significantly associated with acute kidney injury $(P=0.26)$.

\section{Discussion}

To our knowledge, this is the largest study evaluating the incidence and impact on in-ICU mortality of an amikacin $C_{\max }$ achieved with a high loading dose of $30 \mathrm{mg} /$ $\mathrm{kg}$. Roger et al. and Galvez et al. evaluated the effects of a dose of $30 \mathrm{mg} / \mathrm{kg}$ of amikacin in 47 and 33 patients, respectively, but did not assess the impact of amikacin concentration on mortality $[8,9]$. In these studies, the median $C_{\max }$ obtained with a loading dose of $30 \mathrm{mg} / \mathrm{kg}$ of amikacin was $75 \mathrm{mg} / \mathrm{L}$. This is consistent with previous studies that reported values ranging from 72.1 to $75.8 \mathrm{mg} / \mathrm{L}[8,9]$. We found that, with a loading dose of $30 \mathrm{mg} / \mathrm{kg}$ of amikacin, the pharmacodynamic $C_{\max }$ target (i.e. $>60 \mathrm{mg} / \mathrm{L}$ for the less susceptible bacteria) was frequently achieved $(81.2 \%$ cases), a rate that is consistent with previous studies $[8,9]$.

Studies by Taccone et al. [7] and de Montmollin et al. [6], in which amikacin concentration following a loading dose of $25 \mathrm{mg} / \mathrm{kg}$ was evaluated, found a high frequency of underdosing $(>30 \%)$. These results prompted an increase in the loading dose of amikacin with the aim 
Table 1 Baseline patient characteristics at intensive care unit admission and at inclusion

\begin{tabular}{|c|c|c|c|c|c|}
\hline \multirow[t]{2}{*}{ Characteristics } & \multirow[t]{2}{*}{ Total $(n=110)$} & \multicolumn{3}{|c|}{ Amikacin $C_{\max }(\mathrm{mg} / \mathrm{L})$} & \multirow[t]{2}{*}{$P$} \\
\hline & & $<60(n=20)$ & $60-80(n=46)$ & $>80(n=44)$ & \\
\hline \multicolumn{6}{|l|}{ At ICU admission } \\
\hline Age (years old) & $61[51-70]$ & $57.5[50.5-69]$ & $63[45-69]$ & $62[55.5-70]$ & 0.521 \\
\hline Male sex & $78(70.9)$ & $14(70)$ & $33(71.7)$ & $31(70.5)$ & 0.986 \\
\hline Weight (kg) & $70[58.2-80]$ & $60[52.5-73.5]$ & $70[58.2-80]$ & $72.5[65-82]$ & 0.029 \\
\hline Body mass index $\left(\mathrm{kg} / \mathrm{m}^{2}\right)$ & $24.6[20.7-28]$ & $21.1[18.5-25.7]$ & $23.7[20.8-27.3]$ & 26.6 [21.9-29] & 0.023 \\
\hline APACHE $\|$ & $23[18-28]$ & $25[21-28]$ & $23[17-28]$ & $22[18-26]$ & 0.309 \\
\hline Simplified Acute Physiology Score 2 & $54[41-68]$ & $62[47-70]$ & 54 [44-63] & $52[40-67]$ & 0.361 \\
\hline History of congestive heart failure & $12(10.9)$ & $1(5)$ & $8(17.4)$ & $3(6.9)$ & 0.177 \\
\hline Liver cirrhosis & $4(3.6)$ & 0 & $2(4.3)$ & $2(4.5)$ & 0.63 \\
\hline Chronic obstructive pulmonary disease & $26(23.6)$ & $5(25)$ & $10(21.7)$ & $11(25)$ & 0.924 \\
\hline Chronic kidney disease requiring dialysis & $9(8.2)$ & $1(5)$ & $2(4.3)$ & $6(13.6)$ & 0.233 \\
\hline Cancer ( $<3$ months) & $16(14.5)$ & $4(20)$ & $10(21.7)$ & $2(4.5)$ & 0.051 \\
\hline Diabetes mellitus & $39(35.5)$ & $7(35)$ & $12(26.1)$ & $20(45.5)$ & 0.158 \\
\hline Immunodepression & $24(21.8)$ & $6(30)$ & $9(19.6)$ & $9(20.5)$ & 0.616 \\
\hline \multicolumn{6}{|l|}{ At the day of aminoglycoside administration } \\
\hline Day since admission & $1[0-5]$ & $1[0-6]$ & $0.5[0-5]$ & $1.5[0-6.5]$ & 0.834 \\
\hline Emergent surgery & $25(22.7)$ & $9(45)$ & $12(26.1)$ & $4(9.1)$ & 0.005 \\
\hline Sequential Organ Failure Assessment score & $10[8-11]$ & $10[9-11]$ & $10[7-12]$ & $10[8-12]$ & 0.950 \\
\hline Weight (kg) & $70[60-80]$ & $66[55.5-79]$ & $71[58.2-80]$ & $72[65.5-82]$ & 0.104 \\
\hline Weight gain since ICU admission (kg) & $0[0-3]$ & $0[0-3]$ & $0[0-2]$ & $0[0-2]$ & 0.847 \\
\hline Extracorporeal membrane oxygenation & $15(13.6)$ & $4(20)$ & $5(10.9)$ & $6(13.6)$ & 0.611 \\
\hline Catecholamines & $89(80.9)$ & $16(80)$ & $36(78.3)$ & $37(84.1)$ & 0.776 \\
\hline Norepinephrine ( $\mu \mathrm{g} / \mathrm{kg} / \mathrm{min})$ & $0.44[0.1-0.93]$ & $0.88[0.11-1.64]$ & $0.46[0.09-0.83]$ & $0.41[0.11-0.81]$ & 0.343 \\
\hline $\mathrm{PaO}_{2} / \mathrm{FiO}_{2}$ ratio & $177[122-264]$ & 155 [90-230] & 203 [140-289] & $159[118-258]$ & 0.234 \\
\hline Renal replacement therapy & $40(36.4)$ & $12(60)$ & $15(32.6)$ & $13(29.5)$ & 0.05 \\
\hline Glomerular filtration rate (mL/min) & $45[18.6-86.2]$ & $22.1[0-90.4]$ & $43.6[24.6-86]$ & $49.7[22.5-83.9]$ & 0.583 \\
\hline Lactate level (mmol/L) & $2.3[1.2-4]$ & $2.7[1.5-4]$ & $2.3[1.2-6.5]$ & $1.7[1.2-3.2]$ & 0.315 \\
\hline Platelet count (G/L) & 204 [97-307] & $170[84-218]$ & 204 [90-340] & 230 [141-325] & 0.113 \\
\hline Hematocrit level (\%) & $29.3[26-31.6]$ & $30.3[26.8-32.7]$ & $29.7[27.3-31.6]$ & $27.7[25.3-31.1]$ & 0.284 \\
\hline Leucocyte count (G/L) & $13.9[8.9-21]$ & $14.1[7.1-17.7]$ & $15.6[8.9-23.2]$ & $13[9.2-20.3]$ & 0.373 \\
\hline Glasgow Coma Scale score & 15 [13-15] & 15 [13-15] & 15 [13-15] & 15 [13-15] & 0.661 \\
\hline Bilirubin level (mg/dL) & $12[8-20]$ & $12.5[9-20]$ & $12[9-29]$ & $12[7-19]$ & 0.657 \\
\hline Prothrombin time (\%) & $66[52-78]$ & $66[57-78]$ & 64 [47-81] & $67[57-78]$ & 0.606 \\
\hline Proteinemia (g/L) & $56[47-63]$ & $46.5[40.5-60.5]$ & $55.5[49-64]$ & $59[51-64.5]$ & 0.007 \\
\hline
\end{tabular}

Results are expressed as the median [25th-75th percentiles] or $n$ (\%) as appropriate APACHE Acute Physiology and Chronic Health Evaluation, $\mathrm{C}_{\max }$ peak plasma concentration, $\mathrm{PaO}_{2} / \mathrm{FiO}_{2}$ partial pressure of oxygen in arterial blood/fraction of inspired oxygen

of achieving a $C_{\max }>60 \mathrm{mg} / \mathrm{L}$ in the highest number of patients $[8,9]$.

In our study, the amikacin $C_{\max }$ between 60 and $80 \mathrm{mg} / \mathrm{L}$ recommended by French guidelines [4] was associated with a reduction in the in-ICU mortality rate. In theory, a $C_{\max }$ of amikacin between 60 and $80 \mathrm{mg} / \mathrm{L}$ would be optimal for treating sepsis caused by less susceptible Enterobacteriaceae and non-fermenting Gramnegative bacterial infections (such as $P$. aeruginosa) with a MIC of $8 \mathrm{mg} / \mathrm{L}$. This is highlighted in a study by
Dubois et al. [14], in which $61 \%$ of the isolated $P$. aeruginosa strains had a MIC of $8 \mathrm{mg} / \mathrm{L}$. However, in patients with severe sepsis or septic shock, aminoglycosides are frequently used in empiric antimicrobial treatment without the causal micro-organisms and their MICs being identified. One of the major potential advantages of using aminoglycoside combination therapy is to broaden antibiotic treatment in cases of resistant bacteria, which may be found in ICUs $[15,16]$. Combination therapy can increase the success of empiric therapy in up to $20 \%$ of 
Table 2 Baseline patient characteristics at intensive care unit admission and at inclusion (survivors/non-survivors)

\begin{tabular}{|c|c|c|c|}
\hline Characteristics & Survivors $(n=64)$ & Non-survivors $(n=46)$ & $P$ \\
\hline \multicolumn{4}{|l|}{ At ICU admission } \\
\hline Age (years old) & 60 [45-69] & $63[57-73]$ & 0.03 \\
\hline Male sex & $49(76.6)$ & $29(63)$ & 0.12 \\
\hline Weight (kg) & $70[60-80]$ & 70 [58-79] & 0.84 \\
\hline Body mass index $\left(\mathrm{kg} / \mathrm{m}^{2}\right)$ & $24.6[20.7-27.8]$ & $24.4[20.7-28]$ & 0.58 \\
\hline APACHE II & $21[17-25]$ & 26 [22-29] & 0.0007 \\
\hline Simplified Acute Physiology Score 2 & $52[41-60]$ & $57[45-73]$ & 0.05 \\
\hline History of congestive heart failure & $6(9.4)$ & $6(13)$ & 0.54 \\
\hline Liver cirrhosis & 0 & $4(8.7)$ & 0.03 \\
\hline Chronic obstructive pulmonary disease & $15(23.4)$ & $11(23.9)$ & 0.96 \\
\hline Chronic kidney disease requiring dialysis & $4(6.3)$ & $5(10.9)$ & 0.38 \\
\hline Cancer ( $<3$ months) & $11(17.2)$ & $5(10.9)$ & 0.35 \\
\hline Diabetes mellitus & $15(23.4)$ & $24(52.2)$ & 0.002 \\
\hline Immunodepression & $16(25)$ & $8(17.4)$ & 0.34 \\
\hline \multicolumn{4}{|l|}{ At the day of aminoglycoside administration } \\
\hline Day since admission & $1[0-5]$ & $2[0-7]$ & 0.32 \\
\hline Emergent surgery & $17(26.6)$ & $8(17.4)$ & 0.26 \\
\hline Sequential Organ Failure Assessment score & $9[7-10]$ & $10[9-13]$ & 0.004 \\
\hline Weight (kg) & $70[60-81]$ & $70.5[60-80]$ & 0.92 \\
\hline Weight gain since ICU admission (kg) & $0[0-2]$ & $0[0-3]$ & 0.62 \\
\hline Extracorporeal membrane oxygenation & $7(10.9)$ & $8(17.4)$ & 0.33 \\
\hline Catecholamines & 49 (76.6) & $40(87)$ & 0.17 \\
\hline Norepinephrine ( $\mu \mathrm{g} / \mathrm{kg} / \mathrm{min})$ & $0.26[0.04-0.61]$ & $0.83[0.41-1.65]$ & 0.0002 \\
\hline $\mathrm{PaO}_{2} / \mathrm{FiO}_{2}$ ratio & $200[140-280]$ & $147[103-259]$ & 0.06 \\
\hline Renal replacement therapy & $19(29.7)$ & $21(45.7)$ & 0.09 \\
\hline Glomerular filtration rate $(\mathrm{mL} / \mathrm{min})$ & $53.5[29.7-90.4]$ & $29.8[0-65.9]$ & 0.008 \\
\hline Lactate level (mmol/L) & $1.7[1.2-3.1]$ & $3.2[1.4-7]$ & 0.01 \\
\hline Platelet count (G/L) & 205 [105-339] & $201[86-270]$ & 0.47 \\
\hline Hematocrit level (\%) & $29.2[26-31.3]$ & $29.7[26-32.4]$ & 0.54 \\
\hline Leucocyte count (G/L) & $15.6[9.4-22.3]$ & $13.4[7.8-18.7]$ & 0.22 \\
\hline Glasgow Coma Scale score & $15[14,15]$ & $15[12-15]$ & 0.23 \\
\hline Bilirubin level (mg/dL) & $12[8-17]$ & $145[9-26]$ & 0.22 \\
\hline Prothrombin time (\%) & $72[57-81]$ & $60[47-75]$ & 0.01 \\
\hline Proteinemia $(\mathrm{g} / \mathrm{L})$ & 58 [49-64] & $52[46-62]$ & 0.1 \\
\hline Amikacin $C_{\max }$ between 60 and $80 \mathrm{mg} / \mathrm{L}$ & $34(53.1)$ & $13(28.3)$ & 0.009 \\
\hline
\end{tabular}

Results are expressed as the median [25th-75th percentiles] or $n$ (\%) as appropriate

APACHE Acute Physiology and Chronic Health Evaluation, $\mathrm{C}_{\max }$ peak plasma concentration, $\mathrm{PaO}_{2} / \mathrm{FiO}_{2}$ partial pressure of oxygen in arterial blood/fraction of inspired oxygen

patients $[17,18]$. A high $C_{\max }$ is therefore likely necessary given that $P$. aeruginosa is one of the most frequently isolated micro-organisms, even in cases of early-onset sepsis $[19,20]$.

We agree with Roger et al. [8] that a lower amikacin $C_{\max }$ may be enough to treat sepsis. In their study, all isolated strains had an amikacin $\mathrm{MIC} \leq 4 \mathrm{mg} / \mathrm{L}$, meaning that a $C_{\max }$ between 32 and $64 \mathrm{mg} / \mathrm{L}$ would be sufficient to meet pharmacokinetic/pharmacodynamic parameters in all patients (i.e. $C_{\max } / \mathrm{MIC}>8$ ) [8]. In the present study, we found that with a high dose of $30 \mathrm{mg} / \mathrm{kg}$ of amikacin, $C_{\max }>80 \mathrm{mg} / \mathrm{L}$ was frequently observed and was associated with higher mortality rates. We did not identify a clear hypothesis to explain the relationship between amikacin concentration $>80 \mathrm{mg} / \mathrm{L}$ and mortality. Similar mortality results were found in a small randomised study of 99 patients by Galvez et al. [9] compared three dosing regimens $(15,25$ and $30 \mathrm{mg} / \mathrm{kg})$ of amikacin in patients with severe sepsis or septic shock. In the 15,25 and $30 \mathrm{mg} / \mathrm{kg}$ amikacin-treated groups, the study found that a 
Table 3 Sites of infection and isolated micro-organisms

\begin{tabular}{|c|c|}
\hline & $N$ \\
\hline Sites of infection & 110 \\
\hline Pulmonary & 57 \\
\hline Catheter & 9 \\
\hline Intra-abdominal & 13 \\
\hline Skin and soft tissue & 6 \\
\hline Urinary tract & 6 \\
\hline Other & 3 \\
\hline Unknown & 16 \\
\hline Bacteraemia & 32 \\
\hline Isolated micro-organisms & 108 \\
\hline Cocci & 24 \\
\hline Staphylococcus aureus & 13 \\
\hline Other staphylococci & 3 \\
\hline Enterococcus spp. & 5 \\
\hline Streptococcus spp. & 3 \\
\hline Bacilli & 84 \\
\hline Enterobacteriaceae & 56 \\
\hline Escherichia coli & 15 \\
\hline Enterobacter spp. & 18 \\
\hline Serratia marcescens & 3 \\
\hline Klebsiella spp. & 14 \\
\hline Other Enterobacteriaceae & 6 \\
\hline Pseudomonas aeruginosa & 21 \\
\hline Acinetobacter baumannii & 2 \\
\hline Other bacilli & 5 \\
\hline None & 36 \\
\hline
\end{tabular}

Table 4 Amikacin pharmacokinetic/pharmacodynamic parameters

\begin{tabular}{ll}
\hline Variable & $\boldsymbol{n = 1 1 0}$ \\
\hline Dose $(\mathrm{mg})$ & $2100[1800-2400]$ \\
Dose $(\mathrm{mg} / \mathrm{kg})$ & $30[29.2-30.6]$ \\
Peak plasma concentration $(\mathrm{mg} / \mathrm{L})$ & $75[66.1-86.1]$ \\
Patients with a peak concentration $>80 \mathrm{mg} / \mathrm{L}$ & $44(40)$ \\
Patients with a peak concentration between 60 and & $46(41.8)$ \\
$\quad 80 \mathrm{mg} / \mathrm{L}$ & $20(18.2)$ \\
Patients with a peak concentration $<60 \mathrm{mg} / \mathrm{L}$ & 0 \\
Patients with a peak concentration $<30 \mathrm{mg} / \mathrm{L}$ & $51(78.5)$ \\
Trough concentration $>2.5 \mathrm{mg} / \mathrm{L}^{\mathrm{a}}$ &
\end{tabular}

Results are expressed as the median [25th-75th percentiles] or $n(\%)$

a Trough concentration was not measured for 45 patients

$C_{\max }>60 \mathrm{mg} / \mathrm{L}$ was reached in 0,39 and $76 \%$ of patients, respectively, but the mortality rate was $0,9.1$ and $22.2 \%$, respectively. This study was not, however, designed to statistically analyse mortality. We found that patients with amikacin overexposures tended to have greater amikacin
Table 5 Multivariate analysis of risk factors for in-intensive care unit mortality

\begin{tabular}{|c|c|c|}
\hline Variables & $\begin{array}{l}\text { Adjusted odds } \\
\text { ratio (Cl 95\%) }\end{array}$ & $P$ value \\
\hline Age (per year increment) & $1.044(1.01-1.08)$ & 0.02 \\
\hline $\begin{array}{l}\text { Norepinephrine (per } \mu \mathrm{g} / \mathrm{kg} / \\
\text { min increment) }\end{array}$ & $3.94(1.9-8.15)$ & 0.0001 \\
\hline \multicolumn{3}{|l|}{ Amikacin $C_{\max }$} \\
\hline Between 60 and 80 mg/L & Reference & Reference \\
\hline$<60 \mathrm{mg} / \mathrm{L}$ & $1.92(0.46-8.24)$ & 0.4 \\
\hline$>80$ mg/L & $3.96(1.54-10.2)$ & 0.004 \\
\hline Prothrombin time & $0.98(0.96-1.01)$ & 0.118 \\
\hline $\mathrm{PaO}_{2} / \mathrm{FiO}_{2}$ ratio & $0.99(0.99-1)$ & 0.28 \\
\hline Diabetes mellitus & $1.6(0.59-4.38)$ & 0.32 \\
\hline $\begin{array}{l}\text { Glomerular filtration rate }(\mathrm{mL} / \\
\text { min) }\end{array}$ & $0.99(0.98-1.01)$ & 0.43 \\
\hline Lactate level & $1.01(0.89-1.14)$ & 0.53 \\
\hline SOFA & $1.03(0.81-1.3)$ & 0.18 \\
\hline
\end{tabular}

The Hosmer-Lemeshow goodness-of-fit test $P$ value was 0.248 . The Nagelkerke and Cox/Snell $R^{2}$ were, respectively, 0.347 and 0.258

$\mathrm{Cl}$ confidence intervals, $\mathrm{C}_{\max }$ peak plasma concentration, $\mathrm{PaO}_{2} / \mathrm{FiO}_{2}$ partial $\mathrm{O}_{2}$ pressure in arterial blood/fraction of the inspired oxygen ratio, SOFA Sequential Organ Failure Assessment

trough concentrations $(P=0.08)$. It is well established that aminoglycosides are associated with nephrotoxicity [21, 22], and that a high amikacin $C_{\max }$ in ICU is associated with higher trough-level concentrations [6]. Nevertheless, it is difficult to consider these high $C_{\max }$ as "overexposure" and further studies are needed. Moreover, recent in vitro and in vivo studies suggest that higher aminoglycosides exposure should be targeted for difficult to treat pathogens $[23,24]$. To date, there is a lack of data on aminoglycosiderelated toxicity in once-daily dose and short-duration aminoglycoside therapy. The present study was not designed to analyse and evaluate the association between acute kidney injury and trough concentration or aminoglycoside $C_{\max }$, in that trough concentrations were not measured in all patients, as suggested by French guidelines [4]. Furthermore, previous studies suggest that aminoglycosideassociated acute kidney injury cannot be solely attributed to aminoglycosides, because other factors are frequently associated with acute kidney injury in the ICU, including sepsis, septic shock or nephrotoxic drugs $[25,26]$.

Despite the current trend to increase doses of antibiotics in ICUs for pharmacokinetic/pharmacodynamic purposes, no beneficial effect on outcome has been clearly demonstrated [6-8]. In clinical practice, in Europe physicians are still using low doses of aminoglycosides, as shown by a recent survey of antimicrobial prescribing practices in ICUs, where aminoglycosides were administered at "low" doses $(5 \mathrm{mg} / \mathrm{kg}$ for gentamicin and $15 \mathrm{mg} /$ $\mathrm{kg}$ for amikacin) [27]. 
This study has severe limitations. Given that it was not a randomised controlled trial comparing different loading regimens, we cannot conclude a direct causal relationship between the amikacin $C_{\max }$ and the mortality rate. We did not evaluate the subsequent amikacin $C_{\max }$ after the first injection of the study, and MIC of isolated bacteria was not determined for amikacin. Although the study population may be considered small, to our knowledge this is the largest cohort to have been selected for evaluating the impact of high doses of $30 \mathrm{mg} / \mathrm{kg}$ of amikacin in patients with severe sepsis or septic shock $[8$, 9]; moreover, other studies confined their analysis to pharmacokinetics/pharmacodynamics parameters $[8,9]$. We agree that analysing pharmacokinetics/pharmacodynamics parameters of medications is one of the first steps before launching an impact study [28]. Nevertheless, aminoglycosides are associated with well-known and severe side effects and analysing outcomes when increasing usual doses is indispensable. Previous studies reported that when high doses of aminoglycosides are administered, sampling within $90 \mathrm{~min}$ of the infusion provides information that leads to the overestimation of the peak serum concentration/minimum inhibitory concentration ratio and to the inaccurate calculation of pharmacokinetic parameters $[29,30]$. Nevertheless, these studies were confined to gentamicin concentrations in a limited number of healthy volunteers $(<13)[29,30]$. By contrast, recent studies [6-10] have reported measurements of amikacin $C_{\max }$ performed $30 \mathrm{~min}$ after infusion, as suggested by French guidelines [4].

\section{Conclusion}

This study suggests that with a high loading dose of $30 \mathrm{mg} / \mathrm{kg}$ the amikacin $C_{\max }$ between 60 and $80 \mathrm{mg} / \mathrm{L}$ recommended by French guidelines is associated with reduced in-hospital mortality, but that it is difficult to achieve in ICU patients $(<50 \%)$. Amikacin overexposure (i.e. $C_{\max }>80 \mathrm{mg} / \mathrm{L}$ ) was frequent and potentially associated with increased mortality.

\begin{abstract}
Abbreviations
APACHE: Acute Physiology and Chronic Health Evaluation; $C_{\text {max }}$ : peak plasma concentration; ICU: intensive care unit; EUCAST: European Committee on Antimicrobial Susceptibility Testing; MIC: minimal inhibiting concentration; SAPS: Simplified Acute Physiology Score; SOFA: Sequential Organ Failure Assessment.
\end{abstract}

\section{Authors' contributions}

Drs. NA, AB, PA and JA had full access to all of the data in the study and take responsibility for the integrity of the data and the accuracy of the data analysis. NA, JA, PA and PM contributed to study concept and design. NA, PA, $A B, A S, D V, J J, B B, R G$ and $L C$ helped in acquisition of data. NA, JA, PA and PM analysed and interpreted the data. NA, JA, AB, AS, DV, JJ, PM and PA drafted the manuscript. $N A, A B, J A, A S, D V, J J, B B, R G, L C, P M$ and $P A$ critically revised the manuscript for important intellectual content. JA, NA, RG and PA contributed to statistical analysis. AB, NA, AS, RG and DV helped in administrative, technical or material support. JA, NA, PM, PA and AB helped in study supervision. All authors read and approved the final manuscript.

\section{Author details}

${ }^{1}$ Réanimation polyvalente, Hôpital Felix Guyon, Centre Hospitalier Universitaire Felix Guyon, Allée des Topazes, Bellepierre, 97405 Saint Denis, France.

2 Département d'Anesthésie Réanimation, AP-HP, Centre Hospitalier Universitaire Bichat-Claude-Bernard, 46, rue Henri-Huchard, 75018 Paris, France.

\section{Acknowledgements}

This work was internally funded. Obtained funding support was provided solely from institutional and/or departmental sources.

Presented in part at the International Congress of the French Society of Anaesthesia and Intensive Care, Paris, France, September 17-19, 2015.

\section{Competing interests}

The authors declare that they have no competing interests.

Received: 11 September 2016 Accepted: 24 October 2016

Published online: 02 November 2016

\section{References}

1. Kumar A, Safdar N, Kethireddy S, Chateau D. A survival benefit of combination antibiotic therapy for serious infections associated with sepsis and septic shock is contingent only on the risk of death: a meta-analytic/ meta-regression study. Crit Care Med. 2010;38:1651-4.

2. Kumar A, Zarychanski R, Light B, et al. Early combination antibiotic therapy yields improved survival compared with monotherapy in septic shock: a propensity-matched analysis. Crit Care Med. 2010;38:1773-85.

3. Moore RD, Lietman PS, Smith CR. Clinical response to aminoglycoside therapy: importance of the ratio of peak concentration to minimal inhibitory concentration. J Infect Dis. 1987;155:93-9.

4. Update on good use of injectable aminoglycosides, gentamycin, tobramycin, netilmycin, amikacin. Pharmacological properties, indications, dosage, and mode of administration, treatment monitoring. Med et Mal Infect 2012; 42:301-308.

5. EUCAST. European Committee on Antimicrobial Susceptibility Testing 2015. www.eucast.org/.

6. de Montmollin E, Bouadma L, Gault N, et al. Predictors of insufficient amikacin peak concentration in critically ill patients receiving a $25 \mathrm{mg} / \mathrm{kg}$ total body weight regimen. Intensive Care Med. 2014:40:998-1005.

7. Taccone FS, Laterre PF, Spapen $\mathrm{H}$, et al. Revisiting the loading dose of amikacin for patients with severe sepsis and septic shock. Crit Care. 2010;14:R53.

8. Roger C, Nucci B, Louart B, et al. Impact of $30 \mathrm{mg} / \mathrm{kg}$ amikacin and $8 \mathrm{mg} /$ $\mathrm{kg}$ gentamicin on serum concentrations in critically ill patients with severe sepsis. J Antimicrob Chemother. 2016;71:208-12.

9. Galvez R, Luengo C, Cornejo R, et al. Higher than recommended amikacin loading doses achieve pharmacokinetic targets without associated toxicity. Int J Antimicrob Agents. 2011;38:146-51.

10. von Elm E, Altman DG, Egger M, et al. The Strengthening the Reporting of Observational Studies in Epidemiology (STROBE) statement: quidelines for reporting observational studies. Lancet. 2007;370:1453-7.

11. Dellinger RP, Levy MM, Rhodes A, et al. Surviving sepsis campaign: international guidelines for management of severe sepsis and septic shock, 2012. Intensive Care Med. 2013:39:165-228.

12. Blaser J, Konig C, Fatio R, et al. Multicenter quality control study of amikacin assay for monitoring once-daily dosing regimens. International Antimicrobial Therapy Cooperative Group of the European Organization for Research and Treatment of Cancer. Ther Drug Monit. 1995;17:133-6.

13. Vittinghoff $E_{1}$ McCulloch CE. Relaxing the rule of ten events per variable in logistic and Cox regression. Am J Epidemiol. 2007;165:710-8.

14. Dubois V, Arpin C, Dupart $V$, et al. Beta-lactam and aminoglycoside resistance rates and mechanisms among Pseudomonas aeruginosa in French general practice (community and private healthcare centres). J Antimicrob Chemother. 2008;62:316-23. 
15. Durante-Mangoni E, Grammatikos A, Utili R, et al. Do we still need the aminoglycosides? Int J Antimicrob Agents. 2009;33:201-5.

16. Leibovici L, Vidal L, Paul M. Aminoglycoside drugs in clinical practice: an evidence-based approach. J Antimicrob Chemother. 2009;63:246-51.

17. Bhat S, Fujitani S, Potoski BA, et al. Pseudomonas aeruginosa infections in the intensive care unit: can the adequacy of empirical beta-lactam antibiotic therapy be improved? Int J Antimicrob Agents. 2007;30:458-62.

18. Beardsley JR, Williamson JC, Johnson JW, et al. Using local microbiologic data to develop institution-specific guidelines for the treatment of hospital-acquired pneumonia. Chest. 2006;130:787-93.

19. Verhamme KM, De Coster W, De Roo L, De Beenhouwer H, Nollet G, Verbeke J, Demeyer I, Jordens P. Pathogens in early-onset and late-onset intensive care unit-acquired pneumonia. Infect Control Hosp Epidemiol. 2007;28:389-97.

20. Allou N, Allyn J, Snauwaert A, Welsch C, Lucet JC, Kortbaoui R, Desmard M, Augustin P, Montravers P. Postoperative pneumonia following cardiac surgery acquired in non-ventilated patients versus acquired in mechanically ventilated patients: is there any difference? Crit Care. 2015;11(19):116. doi:10.1186/s13054-015-0845-5.

21. Paul M, Lador A, Grozinsky-Glasberg S, et al. Beta lactam antibiotic monotherapy versus beta lactam-aminoglycoside antibiotic combination therapy for sepsis. Cochrane Database Syst Rev. 2014;1:CD003344

22. Buchholtz K, Larsen CT, Hassager C, et al. Severity of gentamicin's nephrotoxic effect on patients with infective endocarditis: a prospective observational cohort study of 373 patients. Clin Infect Dis. 2009;48:65-71.

23. Rees VE, Bulitta JB, Oliver A et al. Resistance suppression by high-intensity, short-duration aminoglycoside exposure against hypermutable and nonhypermutable Pseudomonas aeruginosa. J Antimicrob Chemother. 2016 Aug 11. pii: dkw297.
24. Pajot O, Burdet C, Couffignal C, et al. Impact of imipenem and amikacin pharmacokinetic/pharmacodynamic parameters on microbiological outcome of Gram-negative bacilli ventilator-associated pneumonia. J Antimicrob Chemother. 2015;70:1487-94.

25. Boyer A, Gruson D, Bouchet S, et al. Aminoglycosides in septic shock: an overview, with specific consideration given to their nephrotoxic risk. Drug Saf. 2013;36:217-30

26. Taber SS, Mueller BA. Drug-associated renal dysfunction. Crit Care Clin. 2006;22:357-74.

27. Tabah A, De Waele J, Lipman J et al; Working Group for Antimicrobial Use in the ICU within the Infection Section of the European Society of Intensive Care Medicine (ESICM). The ADMIN-ICU survey: a survey on antimicrobial dosing and monitoring in ICUs. J Antimicrob Chemother 2015; 70:2671-2677.

28. Reilly BM, Evans AT. Translating clinical research into clinical practice: impact of using prediction rules to make decisions. Ann Intern Med. 2006;144:201-9.

29. McNamara DR, Nafziger AN, Menhinick AM, et al. A dose-ranging study of gentamicin pharmacokinetics: implications for extended interval aminoglycoside therapy. J Clin Pharmacol. 2001;41:374-7.

30. Demczar DJ, Nafziger AN, Bertino JS Jr. Pharmacokinetics of gentamicin at traditional versus high doses: implications for once-daily aminoglycoside dosing. Antimicrob Agents Chemother. 1997;41:1115-9.

\section{Submit your manuscript to a SpringerOpen ${ }^{\circ}$ journal and benefit from:}

- Convenient online submission

- Rigorous peer review

- Immediate publication on acceptance

- Open access: articles freely available online

- High visibility within the field

- Retaining the copyright to your article

Submit your next manuscript at springeropen.com 